\title{
Magnesium isotope signatures of hydrotalcite supergroup minerals during weathering and carbonation of ultramafic mineral wastes
}

C.C. TURVEY ${ }^{1 *}$, S.A. WILSON ${ }^{2}$,V. MAVROMATIS ${ }^{3}$, J.L. HAMILTON $^{4}$, B.Z. DLugOGORSKI ${ }^{5}$ AND H.C. OSKIERSKI ${ }^{6}$

${ }^{1}$ Bradshaw Research Initiative for Minerals \& Mining, UBC, 2207 Main Mall, Vancouver, BC, Canada

(*correspondence: cturvey@eoas.ubc.ca)

${ }^{2}$ School of Earth and Atmospheric Sciences, University of Alberta, Edmonton, AB, Canada

${ }^{3}$ Institute of Applied Geosciences, Géosciences Environnement Toulouse, CNRS, Toulouse, France

${ }^{4}$ Australian Synchrotron, ANSTO, Clayton, VIC, Australia

${ }^{5}$ Office of Deputy Vice-Chancellor, Research \& Innovation, Charles Darwin University, Darwin, NT Australia

${ }^{6}$ School of Engineering and Information Technology, Murdoch University, Murdoch, WA, Australia

Hydrotalcite supergroup minerals are common components in ultramafic rocks, where they typically form via hydrothermal alteration of spinel minerals. However, they can also form from low temperature alteration of brucite by atmospheric $\mathrm{CO}_{2}$ at the Earth's surface.

Here we test whther $\mathrm{Mg}$ isotopes can be used to distinguish between hydrotalcite formation pathways. Samples of serpentines, brucite and hydrotalcites were taken from three ultramafic mineral deposits in Australia: including sedimentary pyroaurite and coalingite from the Woodsreef chrysotile mine (New South Wales) and metamorphic iowaite-pyroaurite and woodallite-stichtite from the Mount Keith nickel mine (Western Australia) and Dundas mineral field (Tasmania).

Magnesium isotope data for serpentine minerals from all the localities plotted in two distinct regions with: (1) $\delta^{26} \mathrm{Mg}$ values from -0.28 to $0.00 \%$ o $( \pm 0.04 \%$ ), typical of the $\mathrm{Mg}$ content of terrestrial ultramafic rocks, and (2) $\delta^{26} \mathrm{Mg}$ values from $0.00-0.37 \% 0( \pm 0.04 \%$ ), which are enriched compared to the typical $\mathrm{Mg}$ isotope composition of serpentine minerals. This ${ }^{26} \mathrm{Mg}$ enriched serpentine may be due to exposure and preferential (incongruent) dissolution of ${ }^{24} \mathrm{Mg}$ at the Earth's surface during weathering.

The $\mathrm{Mg}$ isotope compositions of hydrotalcite minerals varied from -1.23 to $-0.50 \%( \pm 0.05 \%) \delta^{26} \mathrm{Mg}$, without an apparent differnce due to the formation pathway. This may imply that these minerals exchange $\mathrm{Mg}$ with their environment, a process that could obscure the original hydrothermal signature of some hydrotalcite minerals. 